\title{
Parametric Study on the Influence of Embedded SPR to the Performance of Square CFST Columns
}

\author{
Abdul Azim Abdullah ${ }^{12^{*}}$, Azrul Abdul Mutalib ${ }^{2 *}$, Shahrizan Baharom ${ }^{2}$, Wan \\ Hamidon Wan Badaruzzaman ${ }^{2}$
}

${ }^{1}$ Department of Civil Engineering,

Universiti Malaysia Sarawak, 94300 Kota Samarahan, MALAYSIA

${ }^{2}$ Department of Civil Engineering,

Universiti Kebangsaan Malaysia, 43600 Bangi, MALAYSIA

*Corresponding Author

DOI: https://doi.org/10.30880/ijie.2020.12.09.023

Received 27 August 2020; Accepted 24 November 2020; Available online 30 December 2020

\begin{abstract}
Steel plate reinforcements (SPR) embedded into the concrete core of a concrete filled steel tube (CFST) column is a promising strengthening scheme. However, further study is required to understand the influence SPR on the strength and behaviour of a CFST column. Numerical models of the CFST columns are developed using finite element analysis. The models are verified with experimental results from past research. The models are in good agreement with the experimental study. Then, a parametric study is conducted to investigate the strength and behaviour of CFST columns embedded with various configuration of SPR. In which, the embedded SPR varies in quantity, thickness and height. The parametric study indicates that these factors have positive influence on the performance of the CFST columns. The performance of the columns is measured in terms of strength, stiffness and ductility. Results have shown that the performance of the columns increases with every increment of the quantity, thickness and height of SPR.
\end{abstract}

Keywords: CFST, columns, embedded steel plate reinforcements, finite element analysis, strengthening scheme

\section{Introduction}

Concrete filled steel tube (CFST) columns with circular cross-section have better structural performance compared to square section. It is well known that circular steel tubes provide high confining stress to its concrete core. In contrast, the confining stress distribution of a square CFST sections is non-uniform, hence less confinement. Moreover, the axial strength of a square CFST columns are further reduced when the depth-to-thickness ratio are high due to local buckling [1]-[3]. However, the square CFST members are more preferable due to its high moment capacities, easy beam-tocolumn connections and aesthetic consideration. Researchers have proposed different type of strengthening scheme to improve its strength.

Utilization of longitudinal plate stiffener is a well-known method in improving the resistance of a square CFST column. Longitudinal plate stiffeners are welded on the inner surface of the steel tubes. Experimental tests [3]-[6] have shown that the longitudinal stiffeners can delay local buckling, improves the confinement pressure on the concrete core and thus increasing the resistance and ductility of the CFST columns. The ultimate load of a square CFST columns with one longitudinal stiffener on each steel tube surface was reported to be around 10\% higher than unstiffened sections [7], $[8]$. 